\title{
LOS RELATOS DE GONZALO SUÁREZ. ANÁLISIS DISCURSIVO DE LOS MECANISMOS LITERARIOS Y CINEMATOGRÁFICOS
}

Javier Hernández Ruiz.

En España han abundado los novelistas que han hecho sus pinitos en el guión cinematográfico, pero apenas se ha dado el caso de escritores convertidos en cineastas, quizá con excepciones destacadas como Fidgar Neville o Jesús Fernández Santos, formado en el I.I.E.C. de Madrid y realizador de varios documentales y del largometraje Llegar a más (1963). Gonzalo Suárez pertenece también a esta especie dual escasísima y es cl caso más representativo, espero demostrarlo, de las últimas décadas dentro de un panorama español que no ha brillado precisamente por las propuestas arriesgadas en las relaciones entre literatura y cine.

Suárez comienza su singladura creativa en los años sesenta y se siente inmerso en ese clima de experimentación artística que distingue a la década prodigiosa. Empezó en la literatura, firmando algunos de los libros más frescos y esperanzadores de la narrativa hispana de entonces; en efecto, De cuerpo presente (1963), Trece veces trece (1964), El roedor de Fortimbrás (1964) y, especialmente, Rocabruno bate a Ditirambo (1966) representaban una vía innovadora -diferenciada de las otras rupturas con la estética del realismo social- que se asentaba en la revisión personal de los géneros, las referencias pop estilizadas y la metaficción. Como a Marguerite Duras, la insatisfacción de la narración escrita llevó a Suárez al cine. De igual modo que la valedora del texte-film y Robbe-Grillet (y su ciné-roman), el creador asturiano ha establecido un peculiar diálogo entre los dos medios de expresión a partir de un universo común. Es ésta una relación sumamente creativa que salta por encima de las formulaciones más simplificadoras y recurrentes de ilustración o adaptación. 


\section{JAVIER HERNÁNDEZZ RUI7.}

Los avances en el campo de la narratología y la semiótica permiten a estas alturas acometer con ciertas garantías trayectorias artísticas como la de Suárez, en gran medida fundadas en las siempre problemáticas interrelaciones entre literatura y séptimo arte. Más allá de consideraciones de orden contextual o temático', interesa aquí analizar la problemática narativa en los textos literarios y fílmicos de nuestro autor a la luz de las metodologías arriba citadas. Este campo es, no obstante, muy amplio, por lo que me ceñiré especialmente a cuestiones relacionadas con el discurso - principalmente la estructura, el aspecto y las voces narrativas-. Profundizar en otras parcelas adyacentes, como los procesos de enunciación o las operaciones simbólicas, llevaría demasiado lejos para las pretensiones de un artículo de estas características.

Este estudio comparado es viable en la medida que, como diría Jorge Urrutia en consonancia con otros muchos analistas, "el relato aparece como una estructura común a diversos lenguajes"2. De ahí que la historia del cine haya asumido en buena medida los esquemas narativos primero ensayados en las letras. El denominado lenguaje cinematográfico es, por tanto, "una actualización del lenguaje abstracto que gobierna toda la narración" 3 . Pero en el caso de G.S. hay, además, otro elemento de ligazón: una poética compartida ex aequo entre los dos medios de expresión. Presupuestos teoréticos que empezaron desarrollándose en sus primeras novelas de los años sesenta y que luego, metido a realizador, irá asimilando en su cine a través de un proceso nada fácil en el que los condicionantes comerciales supusicron un freno no siempre superado con éxito.

L.os postulados de esta teoría poética se resumen en el axioma "la realidad es una ficción más", del que se derivan los demás: la subjetividad escindida, los desafíos metaficticios, el protagonismo de lo lúdico, el humor, el artificio especular, etc. Un corpus té́ricot cuyas intuiciones fundamentales quedan definidas en La zancada del cangrejo, texto que Suárez escribió en 1969 (Papeles de Son Armadans, $\mathrm{n}^{\circ} \mathrm{CXCI}$, febrero de 1972, MadridPalma) a modo de declaración fabulada de principios.

Para comprender las nada fáciles transacciones entre el medio literario y el cinematográfico hay que tener presente que éste último está configurado por varios canales de expresión (la palabra, la imagen, la música, los ruidos...) que añade, según Gaudreault, un plus de complejidad respecto a la narración literaria, abundando en las ya de por sí complicadas relaciones entre lo narrado y lo mostrados. La imagen impone sus propias leyes en el discurso

1.- Fstos aspectos los he tratado ampliamente en mi libro Gonzalo Suárez: un combate ganado con la fieción, Festival de Alcalá de Henares, Madrid, 1991 y en mi tesis doctoral La trayectoria creativa de Gonzalo Suarez. Del periodismo a un diálogo inédito cine-literatura, leída en la Universidad de Valladolid en 1993. Fistos estudios descubren a Suárez como un escritor original, copartícipe de las rupturas antinaturalistas de los sesenta, cuya trascendencia todavía no ha sido valorada hoy día suficientemente. Fis un narrador que hace una lectura estilizada de los géneros populares, en la medida que le sirven como punto de partida para dar rienda suelta a su peculiar estilo elíptico, por otra parte asociado a una personal visión del sujeto esquizofrénico y el cuerpo social de un tiempo-el mestro- en permanente explosión.

2.- Imago Litterue. Cine literatura, Ediciones Alfar, Sevilla, 1984, p. 10.

3.- Ibidem, p. 137.

4.- Todo esto ha quedado ampliamente estudiado en el libro citado del Festival de Alcalá (pp. 63-92) y en el capítulo de mi tesis doctoral "Señas de identidad de un universo poético original", pp. 406-449.

5.- Cfr. el capítulo "Narration el monstration au cinéma", en André GAUDREAULT, Du littéraire au filmique. Système du récit Méridiens Klincksieck, Paris, 1988, pp. 105-116. 


\section{I.OS RELATOS DE GONZALO SUÁREZZ}

fílmico, diferentes a las que imperan en el escrito. Por consiguiente, el espacio, el tiempo y la trama quedarán determinados también por esta peculiaridad e incidirán en el proceso narrativo y en las instancias que se despliegan en cada texto fílmico.

¿Cómo afecta toda esta fundamentación teórica en la problemática concreta de las relaciones entre el cine y la literatura de G.S.? Para responder a ello es obligado desmontar los discursos narrativos de las novelas y películas más representativas del autor incidiendo, como se ha adelantado ya, en lo que afecta a lo estructural, el aspecto y las voces. A partir de aquí es cuando de verdad se pueden implementar términos comparativos.

\section{Disposiciones estructurales del discurso narrativo}

En este nivel, que afecta fundamentalmente al esqueleto sobre el que se organizan las historias, se pueden distinguir en la obra de Suárez tres modalidades dominantes compartidas por su literatura y su cine: la estructura convergente, la circular y la de "cajas chinas" o, mejor, mise en abîme. Comenzaré por la primera, que es lo mismo que hablar de líneas narrativas que discurren paralelas para confluir en un momento puntual del relato. Estas historias convergentes, convenientemente jerarquizadas, configuran el relato de Operación Doble dos, y también afectan a narraciones cinematográficas como Aoom, Morbo, Al diablo con amor y Reina zanahoria (de todas ellas di cuenta en mi mencionado libro exhumando los pormenores de este mecanismo de convergencia) ${ }^{6}$.

La disposición circular, tan lograda en algunos relatos escritos del autor, se construye en su cine a partir de los mecanismos literarios asimilados al discurso fílmico; así, en Ditirambo vela por nosotros una voz en off es quien abre y cierra el relato, algo similar ocurre en El lado oscuro y en El extraño caso del doctor Fausto, sólo que aquí al comienzo acapara el plano el narrador extrarrestre y al final sólo se oye su voz over mientras se ve en imágenes a Octavio Beiral -desdoblamiento de Mefistófeles y ¿de él mismo?, habida cuenta de que todos comparten el mismo físico-. En Remando al viento la "pescadilla que se muerde la cola" se circunscribe a través de la narración off de Mary desde los hielos árticos.

Este diseño circular se conforma en La loba y la paloma por medio de elementos predominantemente visuales: la presencia de imágenes recurrentes que abren y cierran el largometraje (el caballo de cartón, la estatua áurea que desencadena la tragedia y la mirada de la adolescente) o haciendo uso de un dispositivo dramático de "simetría cíclica" que sitúa dos escenas de pelea y muerte por la estatua al comienzo y final de la cinta, ambas presenciadas por la impotente mirada de la chica.

Epílogo se gesta a través de un procedimiento mixto más complejo en el que intervienen la banda sonora y la icónica: en la secuencia inicial la cámara ostenta el protagonismo enunciativo por medio de un aparatoso movimiento de grúa que la hace desembocar en el interior de la pantalla catódica, para enlazar con este último plano estático al final del film, aunque acompañado ahora de la voz en off de Rocabruno.

6.- Cfr. Aoom (pp. 184-188), Morbo, con la historia patente de los recién casados y la latente del matrimonio de la casa misteriosa (pp. 210-112), Al diablo con amor (pp. 221-224) y Reina zanahoria (pp. 280-281). 


\section{JAVIER HERNÁNDEZ RUI7.}

Hay que puntualizar que esta película instrumenta este marco circular en un pensado mecanismo de mise en abîme en el que una historia se mete dentro de otra en un proceso ad infinitum? . Este dispositivo es el más complejo dentro de la carrera cinematográfica de Suárez, tal como demostré al desmontar sus distintos niveles de ficción interrelacionados ${ }^{8}$ y supone la feliz traslación al celuloide de los ensayos que el autor previamente había culminado en las letras con Rocabrumo bate a Ditirambo. De alguna manera, aunque se presente con la apariencia de un libro de relatos, Gorila en Hollywood también participa de esta estructura de incrustaciones al estar todas las narraciones cnmarcadas por un prólogo y un epílogo suficientemente representativos, que dan sentido e interrelacionan su "continente" dentro de la problemática de la ficción y metaficción características del autor.

El primer ensayo suariano de las perspectivas abismales dentro del séptimo arte se atisbaba ya en su primer cortometraje Ditirambo vela por nosotros (1966), extraña fábula en la que cl protagonista va desvelando una ficción organizada en diferentes niveles narrativos interrelacionados y en la que no falta tampoco algún guiño metaficticio (la evidenciación de los mecanismos de representación al quedar reflejado el equipo de rodaje en el espejo) ${ }^{9}$. En El extraño caso del doctor Fansto (1969) construirá un edificio estructural más complejo al servicio de la problemática - muy suariana- de los desdoblamientos de los personajes, para desembocar quince años después en la filigrana que supone Epílogo. En este extraordinario film, por si no fuera poco, se añade como tour de force suplementario la incrustación del teatro dentro del cine en la representación escénica de "El extraño caso del joven Hamlet" (Hamlet y la hija de la criada teatralizan la muerte del padre del primero, alevosamente planeada por su tío); el resultado es de vértigo: el espectador ve un filme de Gonzalo Suárez en el que un personaje (Rocabruno) cuenta una historia dentro de la que otro personaje (Hamlet) representa la historia-verídica en el proceso diegético de ese relato concreto- del asesinato de su padre.

\section{Los juegos narrativos: aspecto y voces.}

El discurso narrativo es resultado de la confluencia de un conjunto de actividades que hacen relación a la dimensión espacio-temporal del relato, el uso de los puntos de vista, las voces, el modo, etc. Existen diferencias contrastadas entre un relato literario y otro cinematográfico en el ámbito discursivo, siendo no empero no pocas las parcelas compartidas. En la enunciación fílmica opera la dimensión verbal propia del discurso literario al lado de otras dos (visual y musical). De la sabia conjugación de estas tres coordinadas depende el resultado feliz. de un relato cinematográfico.

Se ha dicho que el caso de G.S. supone un desafío interesante en la medida que se puede cotejar cómo ha organizado los distintos relatos -literarios o fílmicos- partiendo de una temática y una poética compartidas. En este diálogo entre los dos medios se verá que ha existido un trasvase de soluciones discursivas de uno a otro, unas veces con cierto mimetismo (las adaptaciones menos arriesgadas como La Regenta) y otras de manera abiertamente creativa. En este último caso, y en la capacidad del escritor-director para encontrar so-

\footnotetext{
7.- El cuento "Los de abajo" de Gorila en Hollywood se ordena según una estructura regressus ad infinitum.

8.- Ibidem, pp. 306-312

9.- J. HERNÁNDE7., Gonzalo Suárez: un combate..., op. cit., pp. 113-117.
} 


\section{I.OS RELATOS DE: GONZALO SUÁREZ}

luciones narrativas específicas para cada medio de expresión, reside la importancia de la obra suariana desde el enfoque que nos ocupa. Dentro de éste, dos aspectos fundamentales que constituyen el discurso narrativo nos interesan especialmente: el punto de vista y las voces.

\section{La mirada objetiva}

Las experiencias que el autor asturiano ensayó y perfeccionó en sus novelas se incardinan con éxito no pocas veces en la dimensión verbal del relato cinematográfico. La narración se organiza con un sesgo objetivizante (a través de la tercera persona), subjetivizante (primera persona), o por medio de una combinación de perspectivas narrativas que constituyen el modelo más interesante y característico del autor en este ámbito discursivo.

En la obra literaria de Suárez abundan, como es previsible, los relatos literarios narrados en tercera persona y tiempo pretérito -Los once y uno, El roedor de Fortimbrás, Operación Doble dos (1974) y en muchos de Trece veces trece-. En los discursos fílmicos este mismo planteamiento se resuelve por el método más difundido, es decir, por medio de una cámara ubicua que asume la virtual perspectiva del narrador omnisciente. Es el mecanismo que funciona en La Regenta (1974) 10 y en Don Juan en los infiernos (1991). En los cortometrajes El horrible ser nunca visto (1966) y Una leyenda asturiana (1980) el narrador interviene en el discurso por medio de algunos intertítulos, a la manera de los del cine silente en el primer caso y sobreimpresionados en el segundo; desde esta intervención verbal se da paso a ese fluir libre de las imágenes que caracteriza ol medio fílmico y que hace posible el grand imagier, figura instaurada por la tradición francesa.

En las novelas referidas hay ocasiones en las que el que relata esconde sus marcas", aunque en la mayoría las hace patentes. Paralelamente, en las citadas películas se encuentran momentos en los que la cámara -trasunto del "Autor implícito" de Casetti- se hace ostensible, con movimientos intencionales que rompen la consigna de ocultación del cine clásico. En El horrible ser numca visto se concreta en ese travelling de retroceso que cnmarca a través de la ventana al tío y su sobrina en la cama -movimiento que se puede leer como presagio fatal-y en Don Juan en los infiernos su protagonismo es mucho mayor, sobre todo en la secuencia ralentizada del combate final, al pie del castillo de Manzanares del Real, entre el protagonista contra don Luis de Moor y sus sicarios enmascarados.

\footnotetext{
10.- En esta película se simplifica mucho el edificio narrativo construido por Clarín, un discurso predominantemente heterodiegético y de focalización progresiva (al principio los personajes son presentados desde el exterior y luego el narrador se va aproximando a ellos para introducirse en sus pensamientos y sentimientos). Suárez apenas ha aprovechado la riqueza de puntos de vista que existían en el texto decimonónico y que daban pie a jugosas posibilidades entre el "saber" y el "mostrar" en el orden discursivo. Igualmente las posibilidades del estilo indirecto libre, tan importante en la novela y en la novelística naturalista, apenas han sido explotados, muy al contrario de las mejores adaptaciones de la literatura zoliana (Cfr. Juan Manuel COMPANY, El trazo de la imagen, Cátedra, Madrid, 1987).

11.- En el relato "Al volver de Zeta", incluido en Trece veces trece, la impronta del narrador no se explicita en el discurso. Todo se resuelve por medio del diálogo entre los personajes. El narrador queda implícito, apuntando desde el enunciado hacia esa inteligencia ordenadora del texto que es el enunciador.
} 


\section{JAVIER HERNÁNDEZ, RUIZ.}

\section{La perspectiva subjetiva y su problemática cinematográfica}

Desde De cuerpo presente la primera persona, igualmente siempre en tiempo pretérito, contribuye a organizar con frecuencia los textos literarios suarianos. Será predominante en los relatos de Trece veces trece ("¿Quicre usted rabiar conmigo?", "Bailando para Parker", "Desembarazarse de un Crisantemo", "El cadáver parlanchín", "Trece casos de cuya existencia física respondo, puesto que, por su brevedad, se pueden medir", "Epidemia", "Instalación" y "Plan Jac cero tres"), aunque es en La reina roja (Cátedra, 1981) donde con más complejidad opera el mecanismo narrativo. En todos estos textos literarios las marcas de la narración que dicen verbalmente yo (deícticos) se alternan con los diálogos de los personajes, convenientemente introducidos por el sujeto de la enunciación por medio de formas verbales en pasado -"dijo, pensó", etc.-, nuevas improntas de la presencia del cnunciador.

¿Cómo funciona este proceso en los textos fílmicos que equivalen a una organización narrativa en primera persona? Beatriz es una cinta inspirada en "Beatriz" y "Mi hermana Antonia", dos relatos que Valle-Inclán publicó en la última y definitiva edición en vida que hizo de la colección de cuentos Jardín Umbrio. Historias de samtos, de almas en pena, de duendes y ladrones ${ }^{12}$. G.S., en calidad de guionista, ha tomado prestada la disposición autodiegética del segundo relato: Luis adulto cuenta las impresiones de su infancia vividas en el pazo de Porta-Dei y el trazo de esta narración se deja notar en la voz en off que da paso a evocaciones, recuerdos, ensoñaciones perdidas en la Arcadia infantil (el narrador es recreado visualmente en ese tiempo pasado con su apariencia física de niño). Mas por encima de Juan está cl saber narrativo del enunciador con su mirada objetiva (Casetti) que da paso a los puntos de vista subjetivos del niño (ocularizaciones), muy determinantes en la puesta en esecna para impregnar el relato de ese aire evocador ${ }^{13}$.

En Rowing with the Wind la perspectiva subjetiva de Mary Shelley se hace presente retrospectivamente, una vez más, a través de su relato en off. Estas marcas verbales no son, como impone la lógica cinematográfica ${ }^{14}$, omnipresentes, pero hay suficientes indicios de orden icónico que permiten entender que estamos ante un relato de focalización interna: presencia de Mary subrayada por la música o la significación de su mirada, asunción de su punto de vista (ocularización), aparición estratégica de la protagonista abriendo y cerrando el relato en los hielos árticos (lugar desde el que narra por analepsis la historia). Además, existe

12,- Opera Ommia, vol. XII, Sociedad General Española de Librería, 1920. "Beatriz" y "Mi hermana Antonia", junto con "Rosarito" -que también se recoge en esa edición de Jardín Umbrío- fueron publicadas previamente en diversas recopilaciones de novelas cortas bajo los títulos de Femeninas y Corte de amor:

13.- No me detendré por falta de espacio en esta problemática concreta de las ocularizaciones, así como en otras no menos relevantes que afectan a las operaciones textuales o a la definición del campo simbólico.

14.- Muchos autores han señalado que el discurso fílmico tiende a oscilar, cuando desaparecen las improntas verbales, hacia un territorio donde el fluir de las imágenes organizadas por una cámara ubicua y "objetiva" se convierte en la principal instancia narrativa. Más simple, en palabras de Gaudreault, es muy difícil decir "yo" en cine: "Or s'il est possible pour l'instance aparemment responsable du récit oral de se désigner, soi, par l'utilisation de ce déictique par excellence, la chose est ontologiquement impossible pour l'instance responsable, fondamentalement, du récit filmique, instance qui ne peut pas dire "je" (ni son équivalent anglais, espagnol, etc.) car elle ne parle pas... français (ni anglais, ni espagnol). Elle 'parle', como le dit Jost, 'cinéma'. Et tout au plus peut-elle, cette instance, faire dire 'je' par une autre instance qui, d'une part, lui sera subordonnée et, d'autre part, dévra nécessairement, pour ce faire, s'incardiner, s'actorialiser". (A. GAUDREAULT, Du littéraire au filmique. Systeme du récit, Méridiens Klincksieck, Paris, 1988, p. 177.) 
una coartada de orden temático y culturalista: la complicidad del espectador culto (virtual destinatario de la cinta) permite establecer paralelismos entre lo que está pasando en el film y la conocida novela Frankenstein; de ahí que, como postula la película, el imaginario literario de Mary Shelley impregna la fábula fílmica que, para el espectador, queda sesgada inexorablemente por la óptica subjetiva de la novelista inmersa en la diégesis.

Más allá de la perspectiva cognoscitiva de Mary se adivina la actividad de un méga-narrateu $^{15}$ responsable de la arquitectura discursiva del film; esta figura hace posible los planos iniciales y finales, difícilmente focalizados por la narradora. Se trataría de una instancia final que, si pasáramos al terreno del enunciado, identificaríamos con cl enunciador.

Aparentemente similar respecto a la película anterior es la disposición discursiva de El lado oscuro (1991). Esta cinta pensada en principio para la televisión está contada desde la perspectiva dominante de uno de los dos protagonistas -el abogado que interroga al acusado-, aunque para entenderla en todos sus recovecos hay que tener en cuenta las intervenciones del reo (supuestamente contadas por el letrado); quizá por esta reedición del cruce entre narrador y narratario haya que recurrir de nuevo a esa instancia superior, llámese Autor implícito o sujeto de la enunciación, que hace ostensible su estela en el discurso (explica los planos que se escapan a la referencia verbal asociada a la voz en off del narrador, la autonomía de la cámara ubicua y las miradas al objetivo). Son precisamente estas miradas las que desvelan, en su condición de interpelaciones, la complicidad entre enunciador y enunciatario, algo habitual en las narraciones literarias del asturiano'6; a veces también ponen en evidencia el principal instrumento de representación fílmica - la cámara- alejando el relato del "deliberado ocultamiento" característico del Modo de Representación Institucional.

\section{Mise en abîme}

Dentro de los relatos suarianos la tipología más interesante y arriesgada es la que se sustenta en una pantalla de perspectivas narrativas activadas por los desembragues entre los narradores y los narratarios sucesivos que promueve el enunciador ${ }^{17}$. Estos juegos se sustentan frecuentemente en las citadas estructuras de mise en abîme. Rocabruno bate a Ditirambo es la novela en la que se logra de manera plenamente satisfactoria, incluso brillante, esta simbiosis. De este modo se da vida a un relato lleno de sugerencias en el que la metaficción añade una nueva "perspectiva de abismo". Funciona este texto como un caleidoscopio de narradores y narratarios que operan sobre cartas, reportajes y relatos -narados en diferentes personas y tiempos-junto a otras voces narrativas; sin embargo todo cobra una sorprendente

15.- Gaudreault utiliza esta figura a propósito del análisis de Ojos negros, de Mihalkov, donde sirve para diferenciar el discurso del narrador Romano que cuenta su historia en el marco de una "meganaración" controlada por el primero. Asimismo es el méga-narateur quien hace posible el paso del discurso verbal en primera persona de Romano a la cadencia audiovisual que adquiere su propia autonomía y desborda la focalización limitada del personaje de Mastroianni. Ín el caso de Ditirambo, lo veremos, se puede aplicar en parte este esquema, aunque teniendo en cuenta las particularidades del relato suariano.(Op. cit., pp. 179-180.)

16.- Casos claros de interpelación se aprecian en De cuerpo presente o Gorila en Hollywood ("I cos de abajo" y "Epílogo").

17.- Una vez más, Suárez se manifiesta aquí heredero de las búsquedas narrativas que se iniciaron en El Quijote, la obra que más ha influido en su teoría poćtica en no pocos aspectos. 


\section{JAVIER HERNÁNDEZ RUIZ}

unidad a través de los oportunos "desembragues" y debido a la solvencia de los personajes narradores.

Este entramado permite alumbrar abismales jucgos de ficción y metaficción en el seno de un orbe literario sembrado de sorpresas, en el que nada es lo que parece. Tampoco lo es el entramado narrativo inmediato y las relaciones entre las criaturas literarias, aspectos que se desvelan mucho más meditados y alambicados de lo que en principio pudiera pensarse. Por ejemplo, Ditirambo, que se presenta como el narrador inmediato, será descubierto por la mecánica textual como instancia delegada de Rocabruno (en la medida que es un desdoblamieto de su demiúrgica personalidad). El conocimiento y la capacidad para organizar cl relato de Rocabruno parecen desafiar los límites textuales del simple narrador para atribuirse competencias propias de una inteligencia ordenadora próxima al enunciador. Éste es el único que queda por encima, pero todos los demás personajes que han ostentado eventualmente el rol de narradores se revelan al final como vicarios de ese, podemos llamarlo con permiso de Gardies, sous-enunciateur.

¿Era posible injertar esta sucesión de "pantallas narrativas" en el relato fílmico? Suárez lo intentó ya desde su primer cortometraje, aunque sin lograr aquí, lógicamente, los resultados de su mejor novela. Ditirambo vela por nosotros también se organiza cíclicamente gracias a un narrador que se hace presente mediante un recurso de origen literario: la voz over que abre y cicrra el relato. En otro momento del film se hace reconocible en off otra voz de ultratumba atribuible a una instancia narrativa puntual. Esto se conjuga con otros personajes convertidos a su vez en narradores ocasionales de historias secundarias: la vecina que habla en flash-back de su romance amoroso y de la mujer ideal para el protagonista, el señor Estepa que aclara el misterio de su esposa. Ditirambo vive en esta cinta la paradoja de conjugar el papel pasivo de eventual narratario con el más activo del que va esclareciendo la intrincada ficción en la que está inmerso. La instancia heterodiegética que abre y cierra el relato parece conocer lo que se cuenta -como demuestran sus dos intervenciones a propósito de la misión del personaje-, pero su focalización no es absoluta y hay que echar mano de nuevo a una figura supradiegética para resolver el entramado discursivo.

Ditirambo supone un paso adelante en esa misma dirección. Aquí el enunciador deja las huellas de una instancia organizadora a través de algunos carteles que aparecen al principio. Desde esa figura virtualmente objetiva se dejará paso a otros narradores homodiegéticos que cuentan en primera persona; el principal es Ditirambo, pero parcialmente también pueden ser considerados como tales la viuda de Julio Urdiales y Ana Carmona - cuya historia es visualizada en un largo flash-back-. Todos estos narradores vicarios están convenientemente jerarquizados -ligados en una interesante cadena discursiva a sus respectivos narratarios- $y$ hacen valer esa primera condición mediante la voz. en off. Aparentemente asistimos a una narración de focalización interna parcial, en la medida que los acontecimientos se relatan desde la perspectiva autodiegética del periodista, pero, conforme avanza la película, Ditirambo y el espectador sabrán que la viuda era responsable de lo que estaba pasando en la acción. Ella se erige, por tanto, en instancia demiúrgica que más que narrar está provocando la narración. Asistimos, aunque en menor medida, a juegos de estratos narrativos que se habían detectado en Rocabrumo bate a Ditirambo y que penetran en el territorio de la metaficción.

El extraño caso del doctor Fausto también participa de una similar "tela de araña". En un primer grado emerge en campo un narrador extraterrestre -que incluso se atreve a interpelar mirando a cámara-, luego surgen las voces en off de los "seres sin nombre de un lugar no identificado del universo", quienes increpan frecuentemente a los personajes en otra 


\section{LOS RELATOS DE GONZALO SUÁREZ}

forma de interpelación intradiegética. Igualmente la esfinge, $\mathrm{cl}$ androide femenino, Margarita, el interferómetro Mefistófeles, Octavio Beiral intervienen como virtuales narradores, aunque siempre como delegados de esos seres extraterestres que los controlan demiúrgicamente. Más allá se intuye la presencia del enunciador, que hace posible los atrevidos desembragues entre distintos narradores. El problema del punto de vista cs bastante complejo en este relato: por una parte, la focalización predominante que parece pertenecer al narrador extraterrestre; por otra, la visualización durante la mayor parte del metraje a través de imágenes distorsionadas por el gran angular que corresponde a la peculiar visión ( $i$ unida a conocimiento narrativo?) de los "seres de un lugar no identificado del universo". Este conflicto entre mostración y narración se resuelve al final del film cuando ambos niveles -ver y saberconvergen en el personaje de Octavio Beiral, adecuada plasmación fílmica del clímax en la cadena de desdoblamientos que afecta a las criaturas de la película y de otras obras del ovetense.

También estas filigranas discursivas son apreciables en Aoom. Una voz de ultratumba identificable con un narrador que parece situado en el "más allá" interpela al comienzo ("ésta es la historia...") y luego va presentando a los principales personajes que actuarán como narradores delegados. Este papel es asumido, por ejemplo, por el desaparecido actor Ristol, quien cuenta su historia en flash-back a partir de su voz que sale del cassette (y que es escuchada por su prometida Ana en calidad de narrataria). Ese testimonio en off no sólo hará avanzar esta fábula de reencarnaciones en momentos oportunos, sino que clausurará el film sobre un primer plano de la piedra donde ha quedado atrapado el espíritu de Ristol, mientras se escucha su grito desesperado reclamando a su amada. Final insólito y desafiante que puede ser descifrado como una interpelación más hacia el destinatario. En resumen, narración predominantemente homodiegética, como las anteriores, en la que intervienen las focalizaciones internas de Ana y Ristol inscritas en el marco de un saber narrativo superior atribuible al sujeto de la enunciación.

Parranda se construye con una estructura narrativa más estudiada, menos explícita, que su referente literario, A esmorga (1959) de Eduardo Blanco Amor ${ }^{18}$. Las primeras secuencias parece que se cuentan desde esa mirada objetiva de la que hablaba Casetti, pero el inserto de un primer plano de un magullado Cibrián, con la mirada perdida en el objetivo mientras recibe una contundente bofetada, descubre la perspectiva predominante en el relato. Ésta no es otra que la de Cipriano Caneda, alias Cibrián, quien narra coaccionado por los golpes que la Guardia Civil le proporciona en el cuartelillo del pucblo. Estos insertos, en los que siempre aparece en primer plano el protagonista de cara a la cámara y siendo abofeteado por sus verdugos -que se mantienen fuera de campo-, se intercalan varias veces en el relato para recordar al espectador esa focalización interna fija. Desde el planteamiento bettetiniano de la "conversación audiovisual" predominaría en el enunciado una categoría de situación conversativa que equilvadría a "producción de una pregumta y su inmediata satisfacción".

18.- La novela responde a la estructura de un interrogatorio del protagonista Cibrián ante el juez. Las intervenciones del acusado están elididas -se manifiestan en el texto mediante el trazo de los guiones que dan pie a unas preguntas no explicitadas-, por lo que todo el peso corresponde a la versión de los hechos que da Cibrián en primera persona, acomodándose siempre a las cuestiones que le plantea la autoridad judicial. Por tanto, las preguntas del magistrado las intuimos por las respuestas del reo, quien hace referencia a su interlocutor frecuentemente. 
13 cambio de interlocutores de Cibrián a la hora de adaptar a la pantalla -es decir, el juez de la novela por los verdugos de la Benemérita en la película- otorga a la historia filmada un dramatismo y un sentido subversivo mayor que el que permite la opción del libro ${ }^{19}$. Obsérvese, por otra parte, cómo en ambos textos el narratario permanece en off/fuera de campo incrementando de esta manera la sensación de soledad y de indefensión del protagonista. La emergencia final de un narrador inesperado da a entender la existencia de una instancia superior que va delegando el don de contar la historia a Cibrián -con una marcada focalización- y a otros personajes, como ese servidor de la ley capaz de introducir narraciones de segundo grado (el cuento de Maupassant) y de "darle la puntilla a la historia", incidiendo en su último sentido20.

En Reina zanahoria se juega con la doble perspectiva del narrador principal implícito, que predomina en la práctica totalidad de la película, y ese plano final en el que Úrsula Alejandra se erige inesperadamente en narradora interpelando al espectador con un doble gesto suficientemente significativo: mirando a cámara y guiñando un ojo. ¿Es la americana en el fondo quien acapara la focalización del film? Sospecha que puede ser avalada además si tenemos en cuenta que la trama de la cinta nos desvela al final que el personaje de Úrsula es el demiurgo que maneja los hilos de los personajes. Suárez ha dejado para el desenlace, una vez más, la posible solución del entramado narrativo. De esta manera se ilumina todo el relato anterior desde una nueva perspectiva y la narración, en principio presumiblemente heterodiegética, se revela autodiegética con todas las consecuencias.

Epílogo es, sin duda, la película de Suárez donde los procesos narrativos son más apasionantes. Aquí logra el autor concretar cinematográficamente con éxito esa pantalla de perspectivas que tan primorosamente había levantado en Rocabrumo bate a Ditirambo. Voy a intentar desmontar el juego narrativo para poner sobre el tapete su riqueza y originalidad y demostrar que aquí G.S. ha alcanzado en el celuloide la madurez de esos planteamientos discursivos. En la primera secuencia del largometraje el ya comentado movimiento de grúa, que acaba significativamente por introducir la cámara en la pantalla de un receptor de TV, se identificaría con lo que Casetti denomina mirada objetiva irreal ${ }^{21}$. De esta manera, el enunciador, sirviéndose de la evidenciación de los mecanismos representativos, parece indicar: "Ya estamos en la ficción".

Volviendo al nivel discursivo, Laína, la desengañada compañera de Rocabruno y Ditirambo, actúa de narrador delegado por medio de un flash-back que sitúa el relato en un segundo nivel pretérito que comienza cuando Ditirambo llega a casa de su compañero para conminarle a que escriba una historia. Pero, ante la negativa del vicjo cascarrabias, Ditirambo se convierte en narrador del relato de "Ombrages" (a través de la máquina de escribir

19.- J. HERNÁNDEZ, op. cil., pp. 264-265.

20.- lil personaje del juez, que no estaba en la novela, se va descubriendo en todos sus recovecos a medida que avanza el metraje. Su primera aparición es sacando un cadáver de una berlina; lo reencontramos en la bodega custodiando el fiambre que los tres "parranderos" le ayudarán a hacer desaparecer merced a sus dotes persuasivas y fabuladoras. l.uego los protagonistas se topan con él en el prostíbulo, en plena sesión necrófila, y la madame les revela su identidad: es escribiente del juzgado y su mujer le pone los cuernos con el "Cabrito" -cuyas facciones corresponden a las del cadáver-. Fil escribiente cerrará el film aconsejando a la mujer e hijo de Cibrián mientras recogen las cosas del finado: " $Y$ es que las cosas, de hacerlas, hay que hacerlas bien". Todo un alarde de cinismo agazapado en la "respetabilidad social".

21.- El autor italiano pone como ejemplo de esto el famoso travelling de la secuencia final de Citizen Kane en la que la cámara recorre las cajas y objetos amontonados en el sótano de la mansión de Xanadú. F. CASEITI, F. DI CHIO, Cómo analizar un film, Instrumentos Paidós, $\mathrm{n}^{\circ}$ 7, Barcelona, 1991, pp. 248-249. 


\section{LOS RELATOS DE GONZALO SUÁRIZZ.}

se da paso a otro grado de ficción) y, seguidamente, desde su nivel dará paso también por analipsis a diversos episodios de la vida de los dos escritores y su musa. En este nivel -pretérito del pretérito-, unos se cuentan historias a otros actuando alternativamente de narradores y narratarios. A su vez, dentro de las historias los personajes pueden reproducir este mismo ciclo, incluso con algún caso citado de incrustación ("El extraño caso del joven Hamlet"). En el significativo plano final, tras esta exhibición de perspectivas dentro del discurso, emerge una voz. en off familiar. Es el inconfundible timbre de Rocabruno (Paco Rabal) que, de esta manera, se revela como el focalizador último que abarca las sabidurías narrativas parciales de los personajes que controla demiúrgicamente, incluyendo su propia materialización diegética como escritor descreído 22 . Una figura que despunta de nuevo como sous-énonciateur.

La compleja estructura de Épílogo puede compararse, en cierto modo, con la de Citizen Kane, que ha sido lúcidamente desentrañada por Gianfranco Bettetini ${ }^{23}$. Ambos relatos están enmarcados por un significativo prólogo y epílogo que escapa al control de cualquier narrador diegético. En ambos el discurso se organiza a partir de encuestas (incoadas por Thompson y la estudiante de literatura) y podría incluso hablarse de la utilización en el film de Suárez del segundo modelo conversacional que propone Bettetini -"producción de una pregunta y no producción de la 'respuesta' adecuada en el texto"- en el sentido de que hasta el final no se satisfarán los interrogantes. De la misma manera que en la película de Welles el enunciatario pregunta al enunciador cuál es el significado de "Rosebud", en la medida que esto supone desentrañar el enigma, en Epílogo se cuestionaría quién es el verdadero responsable de la historia; el enunciador daría paso a la voz en off de Rocabruno para aportar una solución. De este modo, de la misma manera que el analista italiano afirma que la obra maestra de Orson Welles "puede ser leída como una parábola sobre la consciencia y solre las estrategias de aproximación a lo real" 24 , diríamos que la cinta de Suárez es una parábola en torno a la pregunta que está también presente en el texto: ¿de dónde vienen las historias, quién las cuenta en última instancia?

Muchos otros aspectos apasionantes se podrían abordar en esta memorable película sin salirnos del entramado narrativo, por ejemplo, ¿,cómo se organizan las transiciones entre los distintos niveles?25; esta cuestión y otras relacionadas con diferentes desafíos textuales nos llevarían muy lejos. Me quedaría satisfecho con tal que mi exposición anterior hubiera disipado dudas a propósito de la complejidad y originalidad de los discursos literarios y cinematográficos de Gonzalo Suárez. Ha quedado puesto de manifiesto que son textos organizados con plena conciencia por parte del autor y que responden perfectamente en su dimensión narrativa a los planteamientos de una teoría poética ya comentada. Suárez se ha servido de los ensayos narrativos que había desarrollado en sus relatos literarios para aplicarlos luego al cine. En ambos medios se comparten mecanismos, pero cada uno da lugar a un discurso específico que aquí se ha intentado poner de manifiesto. De ese modo, el asturiano se recorta como un narrador que explora desde una poética personal en campos distintos, consciente de los desafíos que uno y otro entrañan.

22.- Se trata, en cierto modo, de una metalepsis en la que esta instancia narrativa cambia de nivel convirtiéndose en personaje. Cfr. G. GENETll:, "Frontières du récil", Commications, 8, 1967, pp. 290-292.

23.- Cap. 5, "I a conversación de Ciudadano Kane" en La comversación audiovisual. Cátedra, Madrid, 1986. pp. 140-174.

24.- Ibidem, p. 171.

25.- En Gonzalo Suárez: um combate...(pp. 312-316). He desarrollado este aspecto con cierto detalle. 
Pero, además de esta meritoria coherencia respecto a una trayectoria personal, lo cierto es que dentro del contexto español el ejemplo de G.S. es insólito en la medida que ha acometido con valentía y con originalidad el trasvase de la literatura al cine. Y esto no precisamente según los cauces trillados de la adaptación (que se satisface con una mera transcripción del narrador omnisciente literario a la mirada objetiva del cine), sino buscando traducciones adecuadas a los retos de una literatura arriesgada -la que se larvó en las búsquedas de los sesenta- que apenas ha informado el adormecido cine español. Más allá de modas y determinaciones contextuales, Suárez ha seguido fiel-a esos puntos de partida ofreciendo una insólita coherencia a toda su obra literaria y cinematográfica. Los análisis en el ámbito estrictamente narrativo creo que así lo han puesto de manifiesto. 